\title{
INTERVENCIONES ETNOGRÁFICAS A PROPÓSITO DEL SUJETO desplazado: estrategias para (des)movilizar una política de la representación
}

\author{
JuAn RicARdo Aparicio \\ Estudiante DE DOCTORAdo EN ANTROpología, \\ Universidad de Carolina del Norte, Chapel Hill \\ aparicio@email.unc.edu
}

\section{Resumen}

[ STE ARTÍCULO RASTREA LOS EFECTOS QUE HA TENIDO EN COLOMBIA LA PRODUCCIÓN DEL [ sujeto desplazado desde inicios de la década de 1990, sobre quienes han sido nombrados como tal. Por medio de ejemplos etnográficos cuestiona los efectos de la objetivación y estigmatización que se asientan cuando se habla de desplazados en el país, de sus problemas y soluciones, así como de sus expectativas para un futuro. No sólo parto de la base de cómo ya los mismos generan respuestas frente a estos efectos, sino que percibo el artículo como partícipe de las luchas para abrir espacios para que los mismos "desplazados" entren como sujetos epistémicos a determinar sus proyectos de vida individuales y colectivos.

PALABRAS ClAVE: desplazados, representación, intervención etnográfica, gobermentalidad.

\section{Abstract}

T HIS ARTICLE TRACES THE EFFECTS THAT THE PRODUCTION OF THE DISPLACED SUBJECT has had in the people that have been named as such, in Colombia since the beginning of 1990. Using ethnographic examples, it questions the consequences of objectification and stigmatization that sets in when there are discussions in the country about the displaced, their problems and solutions, as well as their expectations for the future. I not only start from the basis that they themselves, generate answers in front of those effects, but I see the article as being part of the efforts to open up spaces so the "displaced" themselves can enter as epistemic subjects to determine their own individual and collective life projects.

KEY wORDS: Displaced, representation, ethnographic intervention, governmentality.

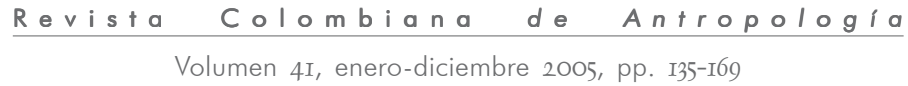




\title{
INTRODUCCIÓN
}

Es desplazado toda persona que se ha visto forzada a migrar dentro del territorio nacional, abandonando su localidad de residencia o actividades económicas habituales, porque su vida, su integridad física, su seguridad o libertades personales han sido vulnerados o se encuentran amenazados, con ocasión de cualquiera de las siguientes situaciones: conflicto armado interno, disturbios y tensiones interior, violencia generalizada, violaciones masivas de los derechos humanos, infracciones a los derechos humanitarios $u$ otras circunstancias emanadas de las situaciones anteriores que puedan alterar o alteren drásticamente el orden público.

Documento Conpes 2804, I995: 4.

\begin{abstract}
(
On esta definición de i995, el Consejo Nacional de Política Económica y Social (Conpes) acogió la dada en I994 por la ricas, para introducir a este nuevo sujeto, el desplazado, dentro de los lineamientos del plan de desarrollo El salto social, del gobierno del presidente Ernesto Samper Pizano (I994-I998). Entre el io y el I8 de junio 1994, por invitación del gobierno de Colombia, Francis Deng, representante del secretario general de las Naciones Unidas sobre desplazamiento interno, visitó el país y elaboró un reporte con conclusiones y recomendaciones, que presentó a la Comisión de derechos humanos de las Naciones Unidas (Deng, E/CN/4/I995/5O/ Add.I). En 1995, la Conferencia Episcopal Colombiana publicó el trabajo Derechos humanos: desplazamiento por la violencia, que, después de hacer el seguimiento estadístico a los datos sobre los desplazamientos forzosos en los diez últimos años, "permitió identificar el problema y convertirlo en un objeto de reflexión en sí mismo" (Secretariado Nacional de Pastoral Social, 200I: I9). En años sucesivos, con la promulgación de instrumentos jurídicos nacionales e internacionales, como el decreto 976 de 1997, la ley 387 de I997 y los Principios rectores del desplazamiento interno de I999, un fenómeno no del todo desconocido en el país empezó a ser un objeto de conocimiento e intervención en el espacio público de Colombia. Muy pronto, nuevos actores distintos al gobierno, como las organizaciones no gubernamentales (ONG), los académicos, los medios de comunicación masiva, los organismos internacionales, las organizaciones de base y los desplazados mismos, entre otros, surgieron para testificar, evidenciar y producir a este nuevo objeto en la historia de la violencia del país.
\end{abstract}




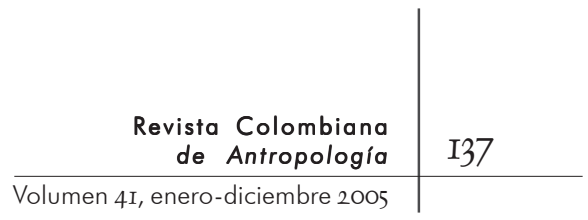

Al hablar de producción de un nuevo objeto no pretendo afirmar que el fenómeno que se intenta denominar bajo esta categoría haya sido inventado por estos actores. Considero que siempre será peor, más grande y más complejo de lo que pueda esperar cualquier persona. La catástrofe humanitaria que han tenido que sufrir las millones de personas que han sido denominadas con este término escapa a las mejores intenciones de entenderla, cuantificarla o visualizarla. No es mi intención pensar que el conocimiento que aporto pueda dar un testimonio más acertado que sirva para comprender mejor el desplazamiento forzoso en medio del conflicto interno que vive Colombia. Con este escrito* sólo intento rastrear los efectos de la producción de este nuevo objeto y su aplicación en nodos estratégicos como el de la política pública, sobre la multitud de cuerpos que son o han sido nombrados como desplazados.

Este deseo se inspiró, en gran parte, en conversaciones que tuve con desplazados a propósito de un proyecto mu-

* Este artículo es producto de reflexiones que se iniciaron a propósito del proyecto Museos cotidianos: espacios de reflexión sobre desplazamiento, identidad y convivencia, adelantado por la división de arqueología y etnografía del Museo Nacional de Colombia y el Instituto Colombiano de Antropología e Historia (ICANH). Agradezco, entonces, por compartir discusiones y experiencias, a las personas desplazadas, anónimas, que sobreviven en medio de la ciudad, o que quizá regresaron a su hogar en medio de todos los temores, con quienes discutí sobre la exposición y sobre su condición misma. A ellas mi más sentido agradecimiento y mi compromiso futuro con su problemática. Debo agradecer especialmente a Margarita Reyes, por su iniciativa, dedicación y compromiso por adelantar este proyecto, a pesar de las dificultades; $y$, sobre todo, por invitarme a hacer parte del mismo. A Juliana Postarini, por su compañía y por las discusiones que tuvimos en el terreno. A mi contacto en la Corte Constitucional, un agradecimiento por enviarme las sentencias y los autos. A Catalina Cortés, Juan Carlos Orrantia, María Clemencia Ramírez y Eduardo Restrepo, por sus comentarios sobre versiones anteriores del artículo. A los evaluadores, por sus sugerencias y comentarios. Como es lógico, a pesar de todas estas ayudas, la responsabilidad conceptual y metodológica es del autor. seográfico alrededor del desplazamiento forzoso desarrollado en el Museo Nacional de Colombia y expuesto en sus salas y en bibliotecas públicas y otros escenarios de la ciudad de Bogotá (Museo Nacional de Colombia, división de arqueología y etnografía/ICANH, 2003). Durante 2003 y parte de 2004, junto con otros investigadores y bajo la dirección de la división de arqueología y etnografía del Museo, que para ese entonces llevaba a cabo un proyecto museográfico y etnográfico sobre la problemática del desplazamiento en Bogotá, visitamos la sede de dos instituciones: la unidad de atención integral a la población desplazada (UAID), un centro de información y de registro para la población desplazada en Bogotá; y el Minuto de Dios, ubicada en Ciudad Bolívar -una de 


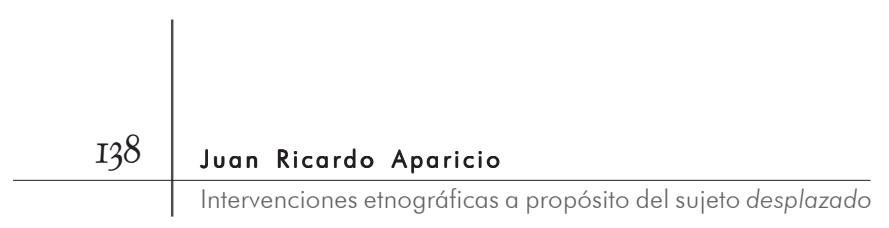

las localidades que más desplazados de la violencia recibe en la capital-, encargada sobre todo de ofrecer paquetes de ayuda humanitaria a desplazados registrados en la Red de Solidaridad Social. Durante varios meses visitamos esas instituciones, hicimos talleres y sostuvimos conversaciones espontáneas con desplazados, mientras esperaban afuera de las oficinas, y entrevistamos también a los funcionarios.

Mediante estas visitas logramos acordar con el Minuto de Dios que nosotros hiciéramos buena parte de las visitas periódicas que sus funcionarios deben hacer a los desplazados luego de darles la ayuda humanitaria. Esto nos permitió ir a los lugares de residencia, donde además de llenar los formularios requeridos, intercambiamos opiniones acerca de distintas problemáticas sobre el desplazamiento forzoso en Colombia, que se presentarán en el artículo. Logramos también consolidar un grupo de desplazados que hizo parte de la construcción de una exposición museográfica colectiva titulada "Yolanda: fragmentos de destierro y desarraigo". Como se dijo, la exposición estuvo en el Museo Nacional de Colombia y en otros espacios, como bibliotecas públicas de la ciudad. Con el tiempo se convirtió, en sí misma, en un lugar de encuentro para iniciar diálogos y otros talleres, y conversaciones con desplazados y con el público asistente sobre algunas de las problemáticas aquí discutidas.

En su conjunto, las conversaciones que tuve durante ese tiempo, y otras que sostengo sobre la problemática del desplazamiento en Colombia y en el mundo, la revisión de investigaciones publicadas y no publicadas, de documentos oficiales y de numerosos artículos de prensa, me han llevado a concentrarme en dos frentes de trabajo académico. Primero, en las diferentes maneras en que se piensa el desplazado en Colombia, es decir, en las técnicas diversas y heterogéneas, siempre relacionadas con operaciones de poder, que convierten y formalizan a este sinnúmero de personas que llegan a la ciudad huyendo de la violencia en el sujeto o, más bien, y de acuerdo con Foucault (1976), en un objeto de conocimiento e intervención: el desplazado. De esas técnicas me ocuparé más adelante. Segundo, en movilizar una política intelectual desde la academia que, consciente y alerta de cómo su misma producción participa también de la subalternización de sus objetos de estudio, lo hace con el deseo de que tal conocimiento pueda abrir fisuras en las opera- 


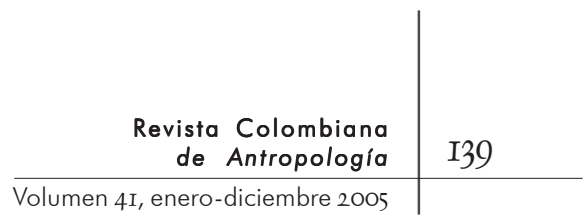

ciones de poder que se concretan en las políticas públicas del estado, para interrumpir los efectos que tienen esas prácticas sobre las personas que llegan a las ciudades huyendo de la violencia. En última instancia, que permita abrir el espacio o que, simplemente, ofrezca herramientas para que los mismas personas que son o han sido nombrados como desplazados aparezcan como sujetos epistémicos ${ }^{1}$ para interrumpir las operaciones de poder.

I. Cuando hablo de "sujetos epistémicos" sigo a Walter Mignolo (2005) en su discusión sobre el sujeto descolonial introducido por el giro epistémico histórico, geo y corpopolítico, que se traduce en que a quienes les fueron negados la razón y la historia las toman por sus propias manos. Estos, según Mignolo, empiezan a participar no sólo como actores políticos, sino, más significativo aún, go de presente las apuestas políticas que hay detrás de las intervenciones académicas en el campo del desplazamiento como epistémicos. forzoso en Colombia. Al llamar la atención acerca de las verdades que sobre los desplazados se elaboran en diferentes ámbitos, y los efectos de poder que tienen en los miles de mujeres y hombres de diferentes generaciones que llegan huyendo de la violencia a las ciudades del país, propongo un marco teórico para vislumbrar una dimensión en la que sea posible pensar cómo estas personas siguen construyendo sus proyectos de vida individuales y colectivos, aun dentro de los discursos elaborados por las operaciones de poder que construyen a este sujeto/objeto desplazado. Cuestiono algunas de las prácticas generalizantes/homogeneizantes de las intervenciones sobre estos sujetos, contraponiendo algunos testimonios producto de la etnografía desarrollada a propósito del proyecto del Museo, para dar cuenta de la heterogeneidad de deseos y expectativas que subyacen a dicha multitud. A partir de esos mismos testimonios, finalizo con ejemplos que me permiten entrever las distintas estrategias de resistencia utilizadas por estas personas dentro y fuera de los lineamientos las políticas públicas sobre el desplazamiento forzoso en Colombia.

\section{DE INTERVENCIONES}

L CARACTERIZAR ESTE ARTÍCULO COMO INTERVENCIÓN EN EL ESCENARIO
de la representación del objeto desplazado, quiero enfatizar
en la doble estrategia que atraviesa el mismo y la apuesta 


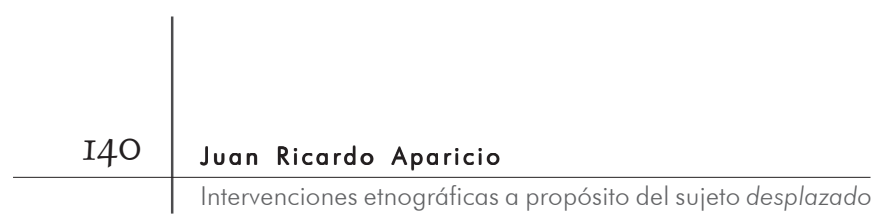

política, que agrupa, a mi modo de ver, algunas prácticas críticas intelectuales de distinta procedencia, académica y no académica. Considero esta apuesta como política en el sentido en que Lawrence Grossberg asume la faceta intervencionista de los estudios culturales en su artículo "Cultural studies: What's in a name?" (I997: 253):

Los estudios culturales son intervencionistas en el sentido en que intentan utilizar los mejores recursos intelectuales disponibles para comprender mejor las relaciones de poder (como el estado de juego o balance en un campo de fuerzas) en un contexto particular, creyendo que tal conocimiento permitirá mejor a las personas cambiar el contexto y, por tanto, las relaciones de poder (traducción del autor).

En este orden de ideas, intento enfatizar en que el desplazado como objeto de conocimiento e intervención mundial surge en la década de 1990 como una construcción política producida en y por relaciones particulares de poder, con efectos concretos para esas personas perseguidas por la violencia en el país. Esta estrategia no pretende ser reveladora ni esperanzadora. Por un lado, buena parte de lo expuesto lo enunciaron quienes intercambiaron opiniones conmigo durante los talleres y conversaciones espontáneas. Este mismo propósito ha sido utilizado, desde otro nivel, por académicos como Liisa Malkii (I995: 377) en su estudio sobre los refugiados en Tanzania. En dicho estudio, ella exploró las formas que toman las intervenciones humanitarias que se enfocan en los refugiados como objeto de conocimiento, de asistencia y de manejo, y rastreó sus efectos en distintos niveles. No obstante, se sabe que los regímenes sobre el refugiado o el desplazado interno son producto de una relación de fuerzas en la que algunos nodos, articulados a la nueva economía global, a políticas de contención promovidas en los niveles locales y globales, a la radicalización de los partidos derechistas en distintas partes del mundo $\mathrm{y}$ al endurecimiento de las políticas migratorias a escala mundial, entre otras, parecen adquirir hegemonía global (Castles, 2003; Lui, 2004). Y, también, que dentro dentro de una concepción del poder que enfatiza siempre en su naturaleza relacional es posible entender que si en efecto existe una relación de poder que se materializa mediante estas operaciones, es porque depende de diversos puntos de resistencia que cumplen el papel de adversarios, blanco, soporte o palanca de esas relaciones (Foucault, I978: 


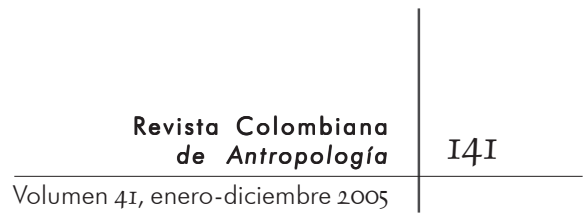

95). Hacer una cartografía de esos puntos de resistencia es uno de los propósitos de este artículo.

\section{Rastreando los efectos de verdad de este nuevo objeto: el estado y los datos}

D ARTO ENTONCES DE CONSIDERAR QUE EXISTE UN CONJUNTO DE REPREsentaciones y verdades sobre este objeto, el desplazado, que en Colombia surge a mediados de la década de I990, cuando el estado lo institucionaliza al ponerlo bajo la tutela de la Red de Solidaridad Social (hoy, Agencia presidencial para la acción social y la cooperación internacional). Atravesado por políticas de distintas escalas -locales, nacionales e internacionales-, su institucionalización logra denotar significados particulares sobre esos cientos de miles de personas. En este sentido, en sus estudios sobre migración forzosa, Sørensen (2003) muestra que en las políticas públicas globales es común concebir al desplazamiento como un fenómeno temporal, y a la población desplazada con una predisposición natural al retorno. Para ella, tales maneras de pensar el desplazado y el desplazamiento han legitimado y autorizado formas particulares de intervención. Al analizar las verdades que se construyen en el caso colombiano sobre el desplazado, mi propósito no es proponer que ellos no son eso o son más que eso, que sea cierto o no que quieran retornar a su lugar de origen, que su situación sea temporal o permanente, ni detenerme en el análisis de las posibilidades ni en la configuración de dicho régimen discursivo. Es analizar estas representaciones en sí mismas, y, sobre todo, en relación con los efectos de verdad que se desprenden de ellas (Foucault, I992).

Para dar un ejemplo: en el documento Conpes citado es posible encontrar, además de la idea de la temporalidad de la que hablaba Sørensen, según la cual el desplazado tiene derecho a recibir asistencia por tres meses $^{2}$, prorrogables excepcionalmente por otros tres, otra idea un poco más perversa que

2. En I995, la asistencia del estado consistía en alimentación, implementos de aseo personal, manejo de abastecimientos, utensilios de cocina, atención médica y psicológica, transporte de emergencia y alojamiento transitorio.

empieza a figurar en las políticas estatales de atención, tal como se plasmaron en documentos iniciales: que el desplazamiento 


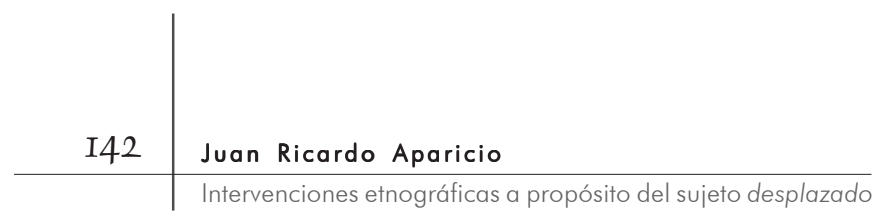

forzado sea el resultado de un desastre natural. No de otra manera se entiende que la financiación y ejecución del programa de asistencia especial de emergencia para el desplazamiento esté a cargo del Sistema nacional de prevención y atención de desastres. Aún más: una investigación del Secretariado Nacional de Pastoral Social (200I) sobre el desplazamiento forzoso en Colombia identificó una situación similar en relación con el decreto 976 de 1997, que antecedió a la promulgación de la ley 387 del mismo año. En ese decreto se asimila al desplazado con el damnificado, y se coloca bajo la protección del Fondo nacional de calamidades. La investigación cita el siguiente fragmento de dicho decreto: "entiéndase de manera similar, a desastres y calamidades, el fenómeno social del desplazamiento masivo de la población civil" (Secretariado Nacional de Pastoral Social, 200I: 29), y concluye que los instrumentos legales que anteceden a la ley del desplazamiento asimilaban de manera directa los "éxodos forzados” con los desastres naturales, con el efecto de pensar al desplazado como víctima de la violencia natural. De este modo se invisibilizaba su dimensión política y se concebía el retorno al lugar de origen como una consecuencia de la atención humanitaria.

Otro de los niveles en los que opera la dimensión macropolítica de este tipo de verdades imbricadas en relaciones de poder es el del fetichismo de los datos, es decir, el asunto de cuántos son los desplazados en Colombia. Un buen ejemplo en este caso lo constituyó la depuración del sistema único de registro (SUR) ${ }^{3}$, para generar "cifras (sic) reconocidas de población desplazada en Colombia que permitieran

3. El sistema único de registro (SUR) es un mecanismo contemplado en el artículo 32 de la ley 387 de I997. Su objetivo es conformar el registro único de población desplazada (RUPD), que busca determinar la demanda efectiva de atención (Codhes, 2003).

4. "Cuántos son". El Tiempo. Bogotá. 23 de mayo de 2003.

personas $^{4}$, dato que a todas vistas buscaba acallar las cifras de la Consultoría para los Derechos Humanos y el Desplazamiento (Codhes), institución de la sociedad civil que desde 1985 ha sido una de las que ha seguido más de cerca el desplazamiento en Colombia, y según la cual el número de desplazados en 2003 se estimaba en más de tres millones. Podría pensarse, incluso, como 


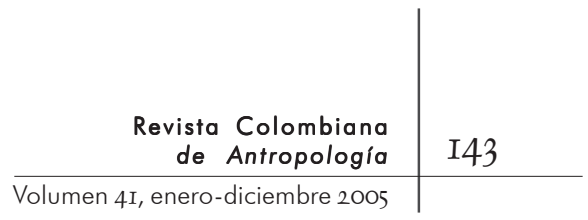

lo propusieron también otros periódicos, que la tasa nacional de desplazamiento forzoso en los últimos años se redujo en cerca de 50\% -de 35I mil a 175 mil casos reportados entre y enero y septiembre de 2003-. Lo anterior sin tener en cuenta que en 2004 los desplazados por la fumigación de cultivos de uso ilícito no fueron acreditados como tales -en un país donde ésta ha aumentado considerablemente-, que existan inconsistencias, temores o rechazo a registrarse en las instituciones, por distintas razones, o que haya una estrategia de guerra que ya no se basa en desplazar a la gente sino en confinarla en lugares específicos y controlados en varias regiones del país, tal como señala Codhes (2004).

En buena medida, en los últimos años gran parte del debate sobre el desplazamiento en Colombia ha estado relacionado con los datos, lo que recuerda el juego político profundo y complejo que hay detrás de las estadísticas (Codhes, 2004a; Piffano, 2004). Scott (1998) ha dicho que los censos, las estadísticas y, en general, el ejercicio de hacer inteligible una complejidad de situaciones cualesquiera mediante su reducción cuantitativa y abstracta cumplen un rol fundamental dentro del estado moderno. El conocimiento sobre estos datos fue, precisamente, lo que llevó a que la Corte Constitucional considerara este fenómeno una de las peores crisis humanitarias del hemisferio ${ }^{5}$. Las discrepancias sobre los datos continúan a través de los años: mientras el gobierno nacional reportaba en 2004 la disminución de 37\% del desplazamiento forzoso con respecto a $2003^{6}$, información que hizo parte, incluso, del discurso pronunciado por el presidente Álvaro Uribe (2002-) en la Asamblea general de las Naciones Unidas, Codhes sostenía que, en realidad, los desplazados habían aumentado $38,5 \%{ }^{7}$. Por lo demás, en 2005 las cifras del Alto comisionado de las Naciones Unidas para los refugiados (Acnur) sobre el desplazamiento forzoso en Colombia ya no situaban al país en el tercer lugar en cuanto a desplazados internos en el mundo, como hace unos años, sino en el primero, con cerca de dos millones ${ }^{8}$.

5. Ibídem.

6. "Gobierno reporta disminución de 37 por ciento

Ahora bien, si se compara la certeza con la que funcionarios de alto nivel, como el presidente de la república o el director de la Red de Solidaridad Social, en el desplazamiento forzado durante el 2004". El Tiempo. Bogotá. I2 de febrero de 2004.

7. "ONG y gobierno se contradicen en cifras sobre desplazamiento forzado durante 2004". El Tiempo. I2 de febrero de 2005.

8. Véase, www.unhcr.org 


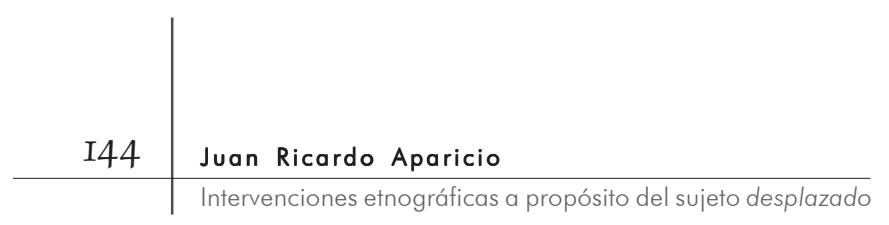

defienden estos datos con lo que se observa en las oficinas donde los desplazados presentan su declaración para ser inscritos en el SUR, es posible encontrar una situación interesante, tanto para nuestro caso en particular como para quien esté interesado en pensar, escuchar y leer etnográficamente al estado. Siguiendo la forma como Gupta (I995) y otros (Abrams, I988; Arextaga, 2000; Ferguson y Gupta, 2005) ${ }^{9}$ se han aproximado al estado considero, luego de visitar esas oficinas, que esos discursos y

9. Para el caso colombiano, véanse Bolívar, 2005; los aparatos institucionales que Ochoa, 2003. intervienen sobre estas personas distan de ser coherentes y eficientes. En las numerosas ocasiones que visité los lugares de atención al desplazado, constaté la precariedad del aparato estatal para clasificar y ordenar, en formularios llenados a mano que se traspapelan con frecuencia, así como para almacenar, distribuir y canalizar los paquetes de ayuda humanitaria dispuestos para ellos. Mi intención no es sostener que debe contarse o llevarse mejor el registro estadístico de esta problemática, sino enfatizar, una vez más, cómo se piensa, lee y escucha al estado desde distintos cuerpos y lugares tales como el de los mismos desplazados y desde esas oficinas periféricas, respectivamente.

De acuerdo con esos autores, planteo que lo que Arextaga (2000) denomina "la realidad ficcional del estado" -distanciado del ciudadano, y en apariencia eficaz y capaz de monitorear y concentrar información como en el caso que nos concierne- es posible, precisamente, por los efectos que producen sus distintos tipos de prácticas. Por las frecuentes visitas que hice a esas oficinas de registro, es difícil pensar estos aparatos y el discurso sobre el desplazado como mecanismos coherentes de arriba abajo, eficaces para centralizar y recolectar información que lleve a determinar los datos oficiales así como para gobernar a la población desplazada. Lo que se observa allí no puede ser más lejano: colas largas, trámites innumerables, burocracias locales, hacinamiento, desorden y pérdida de la información, esperas prolongadas, negligencia, entre otras, como pruebas de la falta de eficiencia y coherencia de esos aparatos para intervenir sobre estas personas. Ese es el estado para estas personas: fragmentado, incoherente, negligente y poco eficaz en su actuar, en contraste con ese otro estado racional que conoce los datos reales sobre el desplazamiento forzoso en el país. Incluso, al hablar 


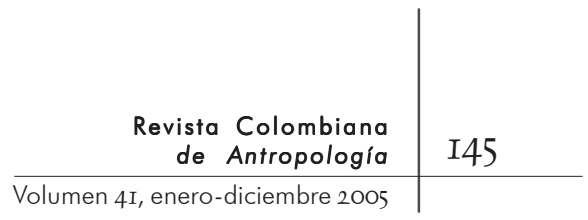

de la política pública, investigadores como Vidal (2002) no dudan en señalar que no existe en sí; lo que existe, para ese autor, es un conjunto de políticas que constituyen núcleos relativamente independientes, con lógicas propias, que en algunos momentos coinciden y en otros se contradicen por completo (Vidal, 2002: I83).

\section{Mi intervención etnográfica}

N O OBSTANTE, PROPONGO PENSAR QUE ESTOS PROCESOS DE CONSTRUCción del desplazado, aun cuando discontinuos, fragmentados e incoherentes, pero capaces de elaborar datos tan contundentes sobre el desplazamiento forzoso en Colombia, no son fijos y están amenazados permanentemente por lo que los sujetos representados por estos discursos hacen de los mismos. En este sentido, anunciar al sujeto -desplazado- es anticipar a uno que ya está constituido, sin que esto implique afirmar que el sujeto esté determinado, tal como lo planteó Butler (200I) para el sujeto mujer. Aquí, como ejemplifica Chaves (2003) para el bajo Putumayo con el caso de los cabildos multietnicos y las identidades depuradas que luchan contra y dentro de las definiciones estatales de la etnicidad, subrayo y enfatizo cómo, en algunos casos, estas determinaciones configuradas desde las políticas públicas son tan solo un primer momento de lo que luego son luchas culturales verdaderas y muy activas de los grupos así marcados, por reconceptulizar, resistir y acomodarse a estas categorias impuestas por el estado.

La conceptualización de Hall (I992) acerca de la identidad me sirve para tener una perspectiva que conjuga el análisis mediante el cual ciertos sujetos se producen a través de una rejilla de inteligibilidad pero también por lo que esos sujetos "hacen de su historia”, aun cuando no bajo las condiciones elegidas por ellos, como lo planteó Marx (I978). El mismo Hall (I992: I2) diría que buena parte del análisis del primer Foucault con respecto al sujeto privilegió el poder monolítico de los discursos, con el efecto de descuidar cómo se negocian y resisten internamente, más allá de la idea de cuerpos dóciles y sin poder de decision sobre sus proyectos de vida individuales y colectivos. Foucault mismo (I992: 49), en sus últimas épocas, sostuvo que quizás insistió demasiado en 


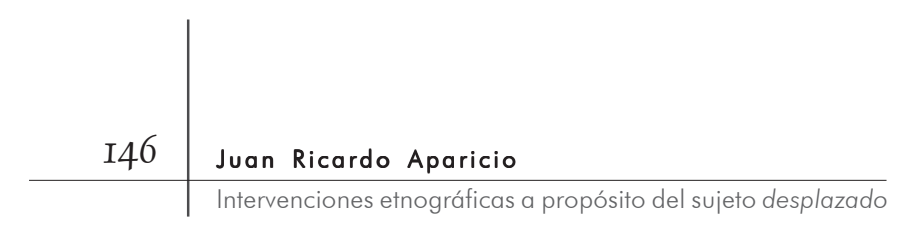

la dominación y el poder, y que entonces estaba más interesado en la interacción entre uno mismo y los demás, así como en las tecnologías de la dominación individual. En esa misma línea, sigo el camino metodológico propuesto por McRobbie (I996: 36) en su estudio sobre las representaciones de la sexualidad, la raza y la juventud en Londres en la década de I990: de cómo estos discursos - de la sexualidad, de la juventud y de los desplazados, en nuestro caso- necesitan adquirir carne y ser explorados dentro del paisaje de las relaciones sociales cotidianas.

En esta dimensión encuentro ejemplos de lo que hacen esas personas en su cotidianidad con esos discursos; como intento mostrar, se los apropian y dirigen hacia otras direcciones no previstas por las operaciones de poder. Así, por ejemplo, existe un proceso por medio del cual el sujeto desplazado puede convertirse en un punto para la reconstrucción de una unidad entre la heterogeneidad de historias personales que alberga esta condición, tal como planteó Hall (1998: 59) con el sujeto negro en Jamaica a finales de los años I960 y I970, en donde las personas reconocieron y aceptaron su herencia negra-esclava-africana. Malkii (1995) explica también, en el caso de los refugiados hutu en Tanzania, de qué manera las personas se han apropiado de esa categoría -el refugiado- como una dimensión positiva de su identidad colectiva en el exilio. En Colombia existen testimonios que hablan de un reconocimiento positivo de este sujeto, como puede inferirse de las palabras de algunos líderes de la difundida y prolongada toma al edificio de la Cruz Roja en Bogotá, en I999, autodenominada "la toma del milenio", con quienes intercambié opiniones mientras observaban la exposición museográfica del Museo Nacional de Colombia, en mayo de 2003.

Uno de ellos hizo referencia a cómo el término desplazado no denota un estigma para él, sino que expresó estar orgulloso de tal rótulo, pues hace referencia al espíritu permanente de lucha y de renovación constante que, según él mismo, se evidenció con la toma citada. Al analizar el caso de los cocaleros del Putumayo durante las marchas de 1996, Ramírez (200I) había planteado el surgimiento de identidades politizadas entre personas que sufren la estigmatización y el abandono del estado. Ella insiste en el surgimiento de esas identidades cuando un grupo emerge como tal porque otro lo excluye y le pone una etiqueta, y los rotulados se identifican como miembros de ese grupo sobre la base de su condición de desamparo. En el caso que nos 


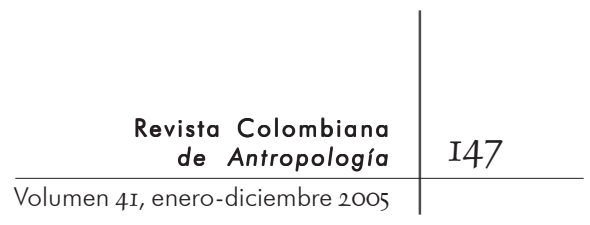

concierne, esta identificación fue muy reveladora cuando en el trayecto al Museo varios líderes corrieron para aparecer en una cámara de City TV, un canal de Bogotá que entrevistaba a los transeúntes. Fue revelador en tanto ese deseo manifiesto de visibilizarse va en contravía de todo un régimen de representación que los hace invisibles y anónimos.

Así, frente al desdibujamiento de la persona, que se diluye entre el régimen de representación del dato o de la población desplazada, los testimonios que presento, tomados de la etnografía coyuntural y situacional, buscan ubicar a las biografías de estas personas como aquello de lo que se debe (deseo) hablar cuando se habla de desplazados. $\mathrm{O}$, al menos, para recordarle a este régimen de representación la heterogeneidad de deseos, intereses y expectativas que constituye este bloque nombrado como los desplazados y que escapa de su deseo de gobernarlo. En sí, tal como describe Salcedo (2005), mediante las distintas estrategias de sobrevivencia de los desplazados -asociaciones, redes de ayuda, puestos de comida y organizaciones-, los grupos sociales y culturales subalternos subvierten una y otra vez el orden social de las ciudades, así como su condición de marginación (véase Bello y Mosquera, I999). Las conversaciones que mantuve durante ese tiempo señalan este camino: desafiando, afirmando, ignorando, debatiendo y confrontando siempre las representaciones de la política pública y las prácticas que se desprenden de ellas.

\section{DE REPRESENTACIONES Y PRÁCTICAS}

LGUNOS SEÑALAN UNA DE LAS PRÁCTICAS GENERALIZADORAS QUE EXIS-
te en una política pública, la del retorno, como una de las
posibilidades que anhelan muchos desplazados; no obstante,
algunos de los que entrevisté, a pesar que estableciéramos como
hipótesis la finalización del conflicto armado y plenas garantías
para su retorno, ni siquiera contemplan la posibilidad de regresar
a su lugar de origen. De acuerdo con la política pública, el retorno
es voluntario y se llevará a cabo de acuerdo con las previsiones
en materia de proteccion, consolidación y estabilización econó-
mica contempladas en la ley 387 de I997 (Red de Solidaridad So-
cial, 200I: 32). Uno de los objetivos del "Desarrollo y consolidación 


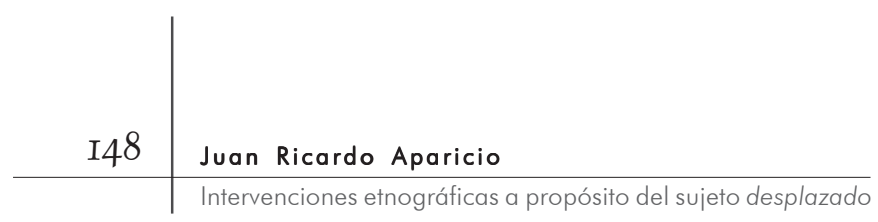

de los programas de restablecimiento de la población desplazada" -parte de las estrategias de atención al desplazamiento interno de la Red de Solidaridad Social- es "generar, con las propias comunidades y familias desplazadas, y en colaboración con las agencias y entidades públicas y privadas, condiciones para el retorno voluntario a sus lugares de origen" (Red de Solidaridad Social, 200I: 32).

Sin embargo, al contrastar esos ordenamientos de la política pública con la cotidianidad de los desplazados con quienes me entrevisté, además de hallar estrategias de supervivencia en el nuevo entorno, no anticipadas y alejadas de esa política, encontré resignación en cuanto a que no habrá condiciones para el retorno voluntario ${ }^{10}$. Hay una diferencia considerable entre los lineamientos de la política pú-

IO. Efectivamente, como lo sostiene la Corte Constitucional, "esta preocupación se ha concretado en los procesos de retorno de Morales (Bolívar), San Francisco (Antioquia), Tambo (Cauca), Micoahumado, municipio de Morales (Bolívar), Tame, Caimanero, Corazón de Jesús y Piedra Candela (Arauca), Betoyes y Bojayá (Chocó), y Santa Teresa, del municipio del Líbano (Tolima), en donde han ocurrido asesinatos de líderes, así como masacres, se han detectado campos minados, o la ocurrencia de nuevos desplazamientos" (Corte Constitucional. Auto I78 de 2005).

minutos, mientras que en la selva debían caminar más de una hora para llegar. Dijo también que no pensaba regresar porque no tenía sentido volver a un lugar donde no había nadie y sólo había desolación y no-futuro. El testimonio del indígena, quien vive en la ciudad de vender dulces en los buses, señala de nuevo lo contrario: piensa quedarse en la ciudad y no en regresar a su lugar de origen. Es significativo que sea un indígena quien diga estas palabras, en tanto investigadores relacionados con la problemática del desplazamiento forzoso en Colombia los caracterizan, junto con los afrocolombianos, los gitanos, los raizales y los campesinos, como "culturas territoriales", que “(...) están estrechamente ligadas a lugares que se entrelazan para conformar un territorio, que han consolidado fuertes referentes comunes y que cuentan con un conjunto organizado e identificable de "significados" y, por ende, comparten universos de sentido (cosmovisiones) similares" (Suárez, s. f.). 


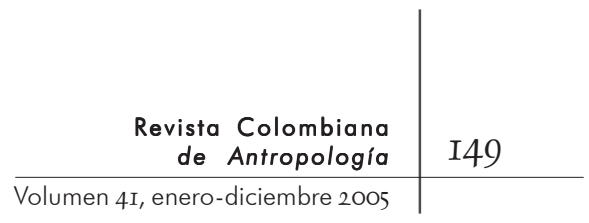

Atrae mucho pensar que tales apreciaciones se desprenden de modelos de pensamiento modernos, según los cuales la identidad está atada al territorio de origen. Malkki (I992) ha llamado la atención sobre la metafísica sedentaria de buena parte de las representaciones sobre los refugiados, por ejemplo, la de los medios de comunicación masiva, en los que se les concibe sin identidad, por estar fuera de su territorio nacional. No quiero insinuar que tales concepciones sean equivocadas, es decir, que la identidad no tenga vínculo alguno con el territorio de origen, pues es claro que, como dice Escobar:

el lugar todavía sigue siendo importante en la vida de muchas personas, quizá la mayoría, si entendemos por el lugar la experiencia de una locación con alguna medida de territorialidad (sin embargo, inestable), algún sentido de fronteras (no obstante, permeables) y en conexión con la vida cotidiana, aun si la identidad se construye, está atravesada por el poder y nunca fija (200I: I40. Traducción del autor).

Sólo señalo que la pérdida del lugar es una experiencia dramática para estas personas, pero que no significa que hayan perdido su identidad o su lugar en el mundo. Lo que se constata es, precisamente, la existencia de habilidades para hacer "lugar" (Escobar, 200I) en el nuevo entorno, sin romper por completo los lazos con lo que se tuvo que abandonar, tal como se infiere de la respuesta de un desplazado del Huila cuando le pregunté por qué guardaba tantos discos de rancheras: respondió que los escuchaba para no olvidar su tierra. $\mathrm{O}$ el caso del indígena desplazado del Putumayo, que para no olvidar la selva conservaba un viejo loro que deambulaba por su casa -humilde-en Ciudad Bolívar. En este y en otros casos, lo que encontré, y el término es de James Clifford (I997: 257) para referirse a las comunidades diaspóricas, lejos de las lecturas de pérdida y de desarraigo, es un sentido permanente de "renovación".

No quiero decir tampoco que ese sentido de "renovación" está presente en todos. Así, por ejemplo, un indígena desplazado proveniente del municipio de Chaparral (departamento de Tolima) dijo que cuando los indígenas o los campesinos llegan a Bogotá "es como si se sacara un mico de la selva y lo soltaran en la ciudad". Hizo referencia también a que el desplazamiento de indígenas y campesinos puede entenderse como si se sacara un pez del agua y luego se botara "al calor", donde no podía sobrevivir por 
no tener el agua ("el territorio", véase más arriba) como medio vital a su alrededor. Es diciente, sin embargo, que él mismo, aun cuando en la entrevista mencionó que anhelaba regresar a su lugar de origen, representado como un "paraíso", comentó en seguida que no había garantías para hacerlo, por lo que para su futuro sólo esperaba o el reasentamiento en otro lugar del campo distinto al de origen o asentarse permanentemente en la ciudad. Encontré también deseos de varios desplazados por salir de país, señalando Canadá como principal destino.

Mi interés no es dar mayor fuerza a una de las dos opciones, regresar o quedarse en la ciudad; lo que me propongo al presentar esta caracterización es dar cuenta de cómo hay toda una gama de representaciones -la de las "culturas territoriales" es un ejemploalrededor de quienes huyen de la violencia en Colombia; representaciones que pierden su consistencia, muchas veces, si se contrastan a los testimonios de los sujetos del discurso. Lo preocupante es que bajo la de las "culturas territoriales" se está orientando buena parte de la política pública en relación con desplazamiento forzoso en Colombia. Parece entonces que, según esa política, "el retorno" al territorio, independientemente de la voluntariedad o la percepción que tengan esos habitantes sobre sus regiones, sobre la ciudad a la que llegan o sobre las posibilidades reales del retorno seguro a su lugar de origen, se convierte en la solución natural que todo el contingente de desplazados debe seguir, independientemente de sus deseos, temores o percepciones (Fernández y Vidal, 2003). En la práctica, como lo ha manifestado la Oficina del Alto Comisionado de las Naciones Unidas para los Refugiados (Acnur) en su informe de I8 de marzo de 2005 presentado a la Corte Constitucional:

la garantía del respeto del principio de voluntariedad queda en entredicho. Para hablar de voluntariedad tiene que existir la posibilidad de escoger entre diferentes alternativas. En términos prácticos, las opciones se reducen a regresar con el apoyo institucional o permanecer en el lugar de llegada con el límite temporal de tres meses de asistencia humanitaria (Corte Constitucional, Auto I78 2005).

Otra representación muy común en relación con el desplazado se manifiesta mediante el estigma que dicen sentir los marca cuando los denominan como tales. En varias ocasiones mencionaron los términos guerrillero, bandolero, cuatrero u oportunistas, entre 


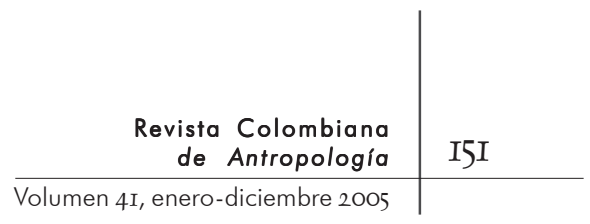

otros, como rótulos que les ponen los habitantes de la ciudad. Explicaron que delante de sus vecinos o frente a sus posibles patrones prefieren no identificarse como desplazados, por las asociaciones que establecen entre el desplazado y la violencia, la criminalidad, la mendicidad, los bandos del conflicto armado, etcétera. Me llamó la atención que muchos de los comentarios que hicieron sobre de la exposición en el Museo Nacional tenían que ver con las percepciones de los habitantes de la ciudad sobre ellos, que les restaban oportunidades para conseguir empleo o entablar amistades en el nuevo entorno. La exposición, consideraban, contribuiría a revertir tales representaciones entre los habitantes de la ciudad.

No todos los desplazados tienen esa percepción sobre los habitantes de la ciudad. Así, por ejemplo, una entrevista con varias personas desplazadas y un líder barrial de Ciudad Bolívar, no desplazado, fue muy diciente al respecto: en sus palabras hizo referencia a que él era también desplazado de esa otra violencia que ha marginado a buena parte de la población colombiana a las franjas de la pobreza en el país. Ver cómo dialogaban sobre las asociaciones barriales a las que se hallaban vinculados, buscando mejorar la situación de los nuevos desplazados, fue un buen ejemplo de tres fenómenos: primero, de cómo las representaciones de los desplazados sobre los habitantes de la ciudad pierden también su consistencia cuando se comparan con la etnografía que se presenta en este artículo. Segundo, y siguiendo a Salcedo (2005), de cómo las ciudades -Bogota en este caso- ${ }^{11}$, se convierten en lugares propios para reconstruir la vida y alejarse de persecuciones letales ${ }^{12}$. Tercero, de procesos de articulación entre desplazados y no-desplazados que optan por formas económicas alternativas de cooperación, para sobrevivir a la marginación estructural que viven.

Lejos de este caso, esperanzador, hay numerosos ejemplos en los que el régimen de representación del desplazado se materializa con unas conseII. "La montaña que acogió a 36 familias. El último refugio de los desplazados". El Tiempo. Bogotá. 31 de julio de 2004.

I2. Véase Gual, Liñan y Martínez (2005) para el caso de otras ciudades, como, por ejemplo, Santa Marta.

cuencias desastrosas. En las conversaciones hubo testimonios de habitantes de la ciudad a quienes les echaban los perros para que no se acercaran a propiedades. La marginación espacial y laboral a la que en muchas ocasiones son sometidos en la ciudad es otro ejemplo de estos 


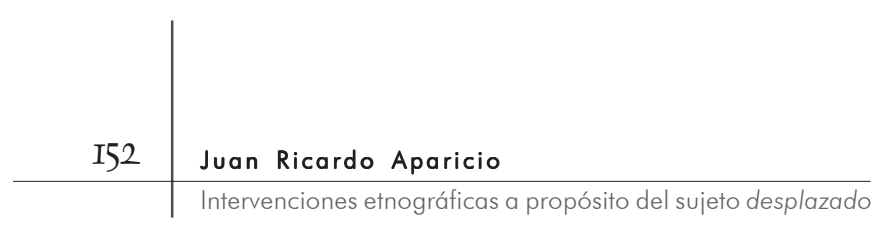

discursos. Castillejo (2000: I88) trae a colación otro ejemplo, relacionado con el reasentamiento propuesto para un grupo de desplazados en el municipio de La Mesa (departamento de Cundinamarca) en 1996. La noticia fue publicada en el periódico El Tiempo el 8 de enero de 1997, y según la misma la gobernadora del departamento asociaba los desplazados con guerrilleros, por lo que se les cerraron las puertas en los nuevos lugares de asentamiento:

Entonces regresaron a Bogotá y el gobierno les consiguió un albergue en La Mesa, al cual nunca llegaron, pues según ellos (los desplazados), la gobernadora dijo que no recibía reinsertados de la guerrilla. En Duitama los concejales y el alcalde aseguraron que en común acuerdo con el gobernador tampoco los podían recibir (los corchetes son míos).

El régimen humanitario, el régimen de los derechos humanos y la gobermentabilidad

XISTE OTRA REPRESENTACIÓN SOBRE LOS DESPLAZADOS TAN PREOCUE pante como las anteriores. Contraria a ellas, no tiene una conL notación explícitamente negativa, quizá por su carácter humanitario. Hablo del régimen humanitario, que convierte la rutina diaria de los desplazados en la ciudad en un ir y venir constante de oficina en oficina y de funcionario en funcionario, tras la asistencia humanitaria ofrecida por el estado. Es común que carguen consigo una carpeta bajo el brazo, en la que guardan, con mucho cuidado, todos los documentos oficiales, los derechos de petición, las tutelas, la carta de salud, los documentos que prueban que son desplazados. Parece que su existencia estuviera cifrada en esas carpetas llenas de ese tipo de documentos. Mientras hablaba con ellos, en las afueras de las oficinas o en sus lugares de residencia, fue usual que me las mostraran para probar que no estaban diciendo mentiras y que eran verdaderos desplazados, o para demostrar la negligencia del estado frente a su obligación de proveerles asistencia, según decretos, sentencias y leyes que guardaban allí. Durante la entrevista que mantuve con uno de ellos en su lugar de residencia, le pregunté qué pasaría si perdiera la carpeta. La respuesta fue 


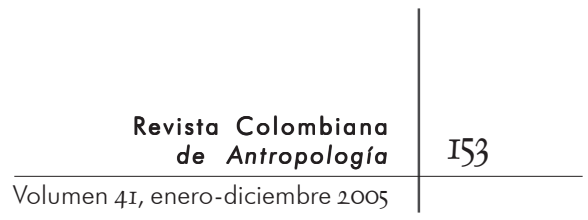

el silencio y una risa nerviosa. Sin embargo, resulta paradójico, como muestro adelante, que parte de sus herramientas de resistencia colectiva e individual frente al estado sean estas carpetas y los documentos que llevan adentro.

A grandes rasgos, se trata de prácticas que ubican y condicionan a estas personas en la posición de simples receptores de ayuda humanitaria, eso sí, siempre y cuando el estado tenga la disposición y destinación presupuestal ${ }^{13}$ (Codhes, 2003). Comparto la opinión de Castillejo (2000) cuando dice que bajo el lema del discurso humanitario estas prácticas des-humanizan a las personas, les quitan su capacidad de poder sobre sus propios proyectos de vida individuales y colectivos, en tanto han sido absorbidas a tal punto por el mismo sistema que ya ni siquiera pueden contradecirlo, refutarlo o criticarlo. Ese es el precio que deben pagar por entrar al sistema. Se trata entonces de una operación del poder que funciona en una dimensión macropolítica para gobernar a la población desplazada mediante la unificación de un proceso que tiene varias etapas y deben seguir todos, independientemente de biografías, deseos o temores. Se trata, en definitiva, de operaciones de gobermentalidad $^{14}$ que traen consigo violencias materiales y simbólicas así como las que expongo en seguida.

Las palabras de una mujer desplazada del departamento de Meta -al oriente del paístal vez logran expresar mejor I3. En algunos casos, estas ayudas las proveen instituciones internacionales como la Acnur o la Organización Internacional para las Migraciones (OIM).

I4. Este término, que aparece en varias partes de la obra de Foucault y principalmente en su artículo "Govermentality" (2000), ha sido tan utilizado que puede considerarse una tradición intelectual, para referirse generalmente a "(...) la conducta de la conducta-esto es, a todas las maneras de pensa y actuar más o menos calculadas y sistemáticas que buscan moldear, regular o manejar el comportamiento de otros, sean los trabajadores de las fábricas, los internos en las prisiones, los pacientes en el hospital mental, los habitantes de un territorio o los miembros de una población" (traducido de Inda (2005: I). Véase Inda (2005) para una compilación reciente de artículos antropológicos que la violencia simbólica y la desutilizan o se relacionan con dicha concepción. esperanza que traen consigo estas prácticas humanitarias de gobermentalidad:

No sé si es por el mismo problema, que cada uno está buscando lo suyo y no haya como hacerle, y por tanta hambre y miseria en que vive mi pueblo, que cuando lo de los regalos de Navidad fue una tragedia. Fue algo que en lugar de dar alegría a la gente le dio tristeza, porque de pronto los regalos no eran los que se esperaban, en la mayor parte de los casos eran cosas que ni siquiera uno necesita. Fue 


\begin{abstract}
tan poquito lo que dieron a la gente, que en lugar de darle alegría le dio tristeza, porque aguantando hambre, sed, sol, porque nos quemamos hasta lo que no teníamos, para aparecernos con eso. A la gente más bien lo que le dio fue rabia. Porque, por ejemplo, a la mayor y a mí nos llegaron un par de zapatos pero talla cuarenta y, ¿quién se los iba a poner?, un poco de pitos que en realidad no tenían razón de ser. Pero algunos estuvieron de buenas y les salieron unas chaquetas; a otros no les salieron sino unos limpiones y no más. Entonces la gente decía, fue más la plata que gastamos en los buses, trayendo la gente o viniéndose uno que lo que realmente se dio. Eso, ¿a qué se debe? No es que uno no agradezca lo que le dieron, es que las necesidades del pueblo son mucho más grandes, mucho más. La gente hubiera preferido de pronto que en sí, que a cada uno le hubieran dado un mercado, una libra de arroz [...] bueno algo así. No, con lo que pasó. Para mí realmente fue algo terrible, si tú hubieras estado, fue terrible, fue tremendo.
\end{abstract}

En este testimonio se observan los efectos de estas operaciones humanitarias, que terminan objetificando a las personas como simples receptoras de cualquier tipo de ayuda o donación externa. En este caso, la donación de unos zapatos de talla más grande termina siendo inútil e inservible, y les recuerda, atreviéndome a poner estas palabras, su condición de miseria y de humillación. Su grado de humanidad es llevado al mínimo posible, haciéndola depender de ayudas humanitarias que ni le son útiles ni puede rechazar. En su conjunto, este tipo de prácticas, cuestionadas por distintos investigadores y por los desplazados, como en este caso, son responsables del enfoque asistencial y coyuntural de la política pública actual sobre el desplazamiento forzoso en Colombia (Castillejo, 2000; Fernández y Vidal, 2003; Suárez, s. f.; Vidal, 2002). Debo mencionar, además, que este debate sobre el nexo entre atención y protección, entendiendo por protección a las acciones que se requieren para asegurar el respeto por la seguridad física y los derechos humanos de la población afectada, ha sido uno de los más fuertes en las discusiones entre organismos internacionales, ONG, académicos que trabajan sobre el régimen humanitario y el de derechos humanos (con respecto a los refugiados y desplazados, véase, por ejemplo, Steiner, Gibney y Loescher, 2003).

Según muchos entrevistados, el proceso humanitario empieza cuando a la persona se le reconoce, oficialmente, como desplazada. Esto supone que alguien les dijo que debían ir a presentar 


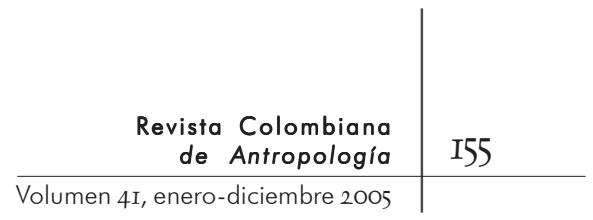

una declaración ante la Red de Solidaridad Social u otra institución relacionada, sea la Cruz Roja o las unidades de atención integral a la población desplazada. Luego de hacer su declaración, en un plazo máximo de quince días quienes son aceptados deben tener una carta de salud, que los legitima como auténticos desplazados ante las autoridades competentes ${ }^{15}$. Durante las semanas siguientes a la entrevista existe la figura de atención de urgencia, que deben brindar las oficinas de atención al desplazado, independientemente de I5. En Bogotá, de acuerdo con información de una funcionaria de una unidad de atención, de cada diez declaraciones sólo se aceptan tres. Con quienes son rechazados no se sabe qué pasa. Existe, además, el subregistro: así, por ejemplo, el de quienes no hacen sus declaraciones por miedo o por desconocimiento. Según Codhes, es de $30 \%$, y según la Red de Solidaridad Social de IO\% (El Tiempo. lación con cada cual. Cuando las instituciones del estado los Bogotá. 23 de mayo de 2003). certifican como desplazados sigue el segundo momento, el de la asistencia humanitaria, la ayuda entregada por esas instituciones durante un lapso de tres meses. Esta última ayuda humanitaria consiste en tres mercados, una provisión de aseo y otra de vivienda, consistente en colchones, utensilios de cocina, etcétera. Después no hay más ayuda asistencial y el estado sólo contempla la financiación de proyectos productivos -con la condición de que se desarrollen en lugares diferentes a las ciudades-, la capacitación -independiente por completo de la posibilidad de un empleo-, o el apoyo para el retorno al lugar de origen.

Es importante mencionar que, en la práctica, los lapsos de quince días y tres meses para la atención de emergencia o de asistencia humanitaria, respectivamente, pueden durar más de un año. Y que la población beneficiada por tales ayudas humanitarias es muy poca, tal como señala la Defensoría del Pueblo, la cual encontró que entre 200I y el 8 de febrero de 2004 de los 170.262 hogares inscritos en el SUR sólo I6.545 (9,71\%) recibieron ayuda humanitaria de emergencia y provisión de aseo (Corte Constitucional. Auto I78, 2005). Así lo ilustra, por ejemplo, el caso de un desplazado del sur del departamento de Tolima, entrevistado en el curso de esta investigación, quien está en Bogotá en silla de ruedas debido a un accidente que tuvo en su lugar de origen, y debió ir, durante casi un año, de oficina en oficina, de reclamo en reclamo, para conseguir las colchonetas y los mercados de su ayuda humanitaria. Como ha indicado Defensoría del Pueblo, es claro que los periodos establecidos por la ley 387 de 1997 son 


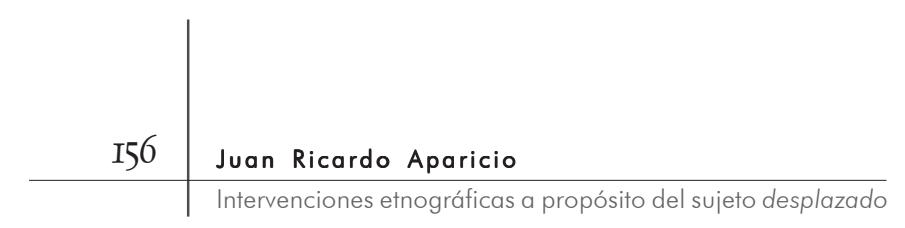

cortos frente a la difícil situación y la falta de celeridad de los trámites para acceder a los programas ofrecidos por el estado (Defensoría del Pueblo, 200I: 60). No digo que este sea el caso de todos los desplazados, pues tuve conversaciones con varios que estaban agradecidos con la Red de Solidaridad por las ayudas recibidas. Así, por ejemplo, durante una entrevista con dos personas de la tercera edad, desplazadas del departamento de Caldas, mostraron las dos o tres colchonetas que les habían donado como la prueba de que el estado les había cumplido.

Mi propósito con estos testimonios es cuestionar el conjunto de prácticas sociales que convierten y construyen a los desplazados en simples cuerpos dóciles, pendientes de la ayuda estatal, brindada como ayuda de emergencia, o en personas interesadas por los recursos y oportunistas ante las posibilidades de atención del estado, que aparece entonces como principal benefactor y víctima de los engaños de estas personas. Son testimonios que hacen alusión, precisamente, al vaivén al cual los someten las instituciones y su promesa de ayuda humanitaria. No quiero plantear que estas ayudas sean una mala idea o algo por el estilo, sino enfatizar, una vez más, en los efectos de esta gobermentalidad, que opera objetificando a un sujeto desplazado abstracto, que no tiene cuerpo ni nombre, y que sólo existe en formularios, inventarios, comprobantes de entrega, firmas que dan constancia de haber recibido las ayudas, etcétera. Además, es importante resaltar, con Ferguson (I994), que este tipo de intervenciones técnicas y apolíticas es el característico de las agencias del desarrollo.

El desplazado se ha convertido, siguiendo a Foucault (I976), no en una persona de carne y hueso que huye de la violencia, sino en un objeto inscrito, clasificado, verificado y, además, despolitizado, silenciado, blanco de múltiples procedimientos que siguen quienes tienen el poder, desde los responsables de su desplazamiento forzoso en su lugar de origen hasta los encargados de los lineamientos de la política pública. Y, más revelador aún,

I6. Véase, por ejemplo, "Más de I.50o habitantes del Caquetá se han desplazado por puesta en marcha del 'Plan Patriota'". El Tiempo. Bogotá. 6 de mayo de 2004. que le quita responsabilidades al estado sobre una problemática que de manera directa o indirecta se relaciona con su actuación -u omisión- ${ }^{16}$, como el caso de las masacres anunciadas, los desplazamientos intempestivos, las operaciones militares tales como las del Plan patriota o, 


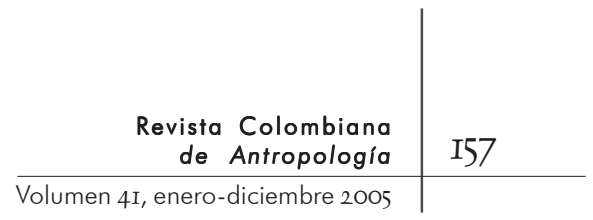

incluso, la entrada masiva y violenta del capital a ciertas regiones del país como la costa pacífica (Escobar, 2004).

Frente a este escenario, el fallo de la Corte Constitucional a la megatutela que responde a más de "Io8 expedientes interpuestos por I.I5O núcleos familiares, todos pertenecientes a la población desplazada, con un promedio de 4 personas por núcleo, y compuestas principalmente por mujeres cabezas de familia, personas de la tercera edad y menores, así como algunos indígenas" (Sentencia T-025 de 2004) ${ }^{17}$ y que obligaba al gobierno nacional a tener una política pública clara y efectiva y a cumplir, antes del 3I de marzo de 2004, con lo dispuesto en la ley 387 de 1997, es una señal entre muchas más de la activa construcción de proyectos de vida individuales y colectivas de estas mismas personas, para recordarle al estado la responsabilidad que tiene con su condición de marginalidad y desprotección ${ }^{18}$.

Aunque la política pública sobre el desplazamiento forzoso en Colombia puede tener su cuota de humanismo para mejorar las condiciones de las familias desplazadas por la violencia, muchos de sus componentes, como la disponibilidad y la asignación presupuestal de recursos o el poco protagonismo de los desplazados en la definición de la misma, son obstáculos para su aplicación. Como dice Francis Deng en su informe, desde I994 el gobierno colombiano ha tenido una cifra récord en cuanto a I7. En dicha sentencia, la Corte declara que la situación en que viven los desplazados representa un "estado de cosas inconstitucional". Al tener en cuenta las denuncias hechas por este grupo de personas, y al revisar los marcos legales existentes hasta ese momento para proteger a la población desplazada, identifica dos problemas estructurales de la política pública actual de atención a la misma: la asignación insuficiente de recursos, que ha estado lejos de los requeridos para obeceder los mandatos legales; y las falencias de la capacidad institucional del estado para responder oportuna y eficazmente a las necesidades de los desplazados (Sentencia T-025 de 2004).

I8. "Corte/Conceden tutela a más de cuatro mil personas". El Tiempo. Bogotá. Domingo 7 de febrero de 2004.

la ratificación de tratados internacionales relacionados con el desplazamiento interno y los derechos humanos en general. Cuando estuvo en Colombia, en I994, el presidente de la república y sus ministros, así como unos funcionarios "jóvenes, tecnócratas, progresivos, abiertos y cándidos" le ofrecieron los mejores servicios durante su estadía, lo que para el ahora ex representante del secretario general de las Naciones Unidas sobre desplazamiento interno ratifica el compromiso formal y diplomático del gobierno colombiano durante todos estos años con las instituciones internacionales relacionadas con el problema del desplazamiento (E/CN.4/I995.50/Add.I.). 


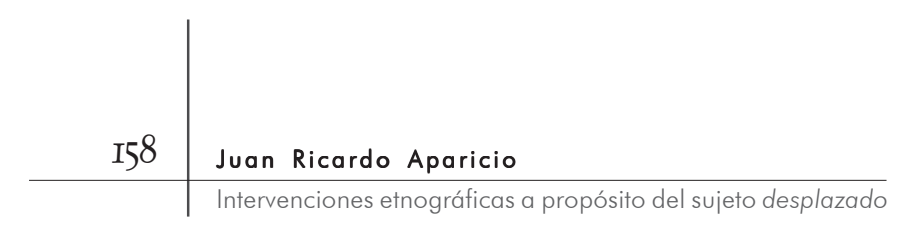

Entre los lineamientos de la política pública de 2001 y 2002 de la Red de Solidaridad Social para la atención a los desplazados, se encuentran, por ejemplo, alusiones a la necesidad de fortalecer el capital humano y social de la población desplazada y a la generación de alternativas productivas que le garanticen sus propias formas de subsistencia (Red de Solidaridad Social, 200I: 32). Como parte de esa estrategia se menciona un programa institucional, tan emblemático que en 2003 todavía existía: los proyectos productivos, consistentes en la creación de asociaciones de desplazados a las que se otorga un capital semilla para que desarrollen proyectos productivos viables en términos mercantiles. Sin embargo, muchos entrevistados critican el programa por diferentes razones: unos no veían con buenos ojos el hecho de tener que asociarse con desconocidos para iniciar un proyecto productivo; otros decían no tener los conocimientos para elaborar una propuesta; y algunos más no se atrevían a regresar al campo para desarrollar su proyecto. En general, todas coincidían en señalar que esta iniciativa estaba destinada a fracasar por ese tipo de dificultades. Llama la atención cómo dicho sistema, a pesar de convertirse en la salida para muchas familias desarraigas, según las mismas, no tenía en consideración sus opiniones o situación actual.

Varias investigaciones han llamado la atención sobre la necesidad urgente de hacer más horizontal y flexible la política pública concerniente al desplazamiento forzoso en Colombia (Acnur, 2002). En los documentos iniciales que nombraban al desplazado en la década de 1990, se habla de la necesidad de establecer una mesa conjunta con las organizaciones de desplazados, para dar asesoría en el diseño y la implementación de las políticas públicas. Incluso dentro de los principios rectores de los desplazamientos internos se recomienda hacer "esfuerzos para asegurar la plena participación de los desplazados internos en la planificación y gestión de su ingreso o de su reasentamiento y reintegración" (Acnur/Defensoría del Pueblo, I999: 29). No obstante, frente a estas iniciativas y luego de constatar cómo la política pública tiene una buena dosis de humanismo al hablar de retorno voluntario y de estabilización socioeconómica -contempladas en la ley-, y al contraste que se percibe en los testimonios de los desplazados, es necesario ser críticos en relación con estos llamados a la participación que, además, ha sido, también, uno de los conceptos de las intervenciones de las agencias de desarrollo (Ferguson, 1992). 


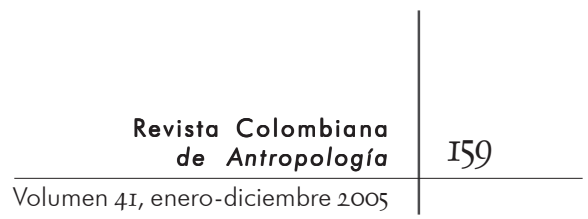

En cuanto al llamado estatal a la participación, no sólo conviene estar de acuerdo con la Corte Constitucional cuando dice que hay "un estado de cosas inconstitucional" en la atención al desplazado, sino que deben cuestionarse las causas subyacentes y profundas -siempre políticas- que hay detrás de la falta de atención por parte del estado a los desplazados, y el apoyo a la política de seguridad democrática del gobierno del presidente Uribe $^{19}$. En este sentido, son llamativos los sucesivos Autos de la Corte Constitucional -por ejemplo, el r78/05-al gobierno para obligarlo a cumplir con su sentencia, en los que sostiene que, meses después de la fecha prevista y a pesar de los esfuerzos, todavía no hay un "avance en el estado de cosas constitucional".

\section{DE RESISTENCIAS Y AUTONOMÍAS}

$\wedge$ HORA BIEN, TAL COMO SE DIJO, ES CLARO QUE VARIAS DE LAS OPERAciones de gobermentalidad descritas son, en algunos casos, sólo el primer momento de lo que luego son luchas culturales. Así, aun cuando varias de las políticas públicas incluyen connotaciones del desplazado como alguien pasivo, temporal y que debe regresar a su lugar de origen, no implican que esté determinado por las mismas (Butler, 200I). Por el contrario: aunque en este artículo tal vez he dado gran importancia al estado, es claro que esas luchas culturales no sólo pasan por la relación estado-desplazado, a pesar de que muchas veces estas personas sostengan su lucha dentro de los mismos espacios de participación abiertos por el estado ${ }^{20}$. Es claro que algunos

I9. Es importante mencionar que como producto de la megatutela mencionada, el gobierno del presidente Álvaro Uribe, mediante el documento Conpes 3400 de diciembre de 2005 ordenó el aumento presupuestal para la atención a la población desplazada, sin duda alguna, bastante superior al de las pasadas administraciones presidenciales en su conjunto. Se trata de una inversión presupuestada de 4,7 billones de pesos para 2005, que contrasta con los $\mathrm{I}, 3$ billones de pesos invertidos durante el periodo 1995-2004. No le resto importancia a este anuncio, pero tampoco quiero celebrarlo por dos razones: primero, porque es todavía un plan de inversión. Pero más aún, lo que he querido demostrar es que parte de los efectos que ha tenido la política pública no se desprenden necesariamente de la escasez o abundancia de recursos. Se trata, más bien, de una configuración que se reproduce precisamente por la construcción de un objeto de conocimiento e intervención, por la asignación de unos expertos encargado/as de diseñarla, y, sobre todo, por la lógica detrás de estas intervenciones que no sólo despolitiza la naturaleza del desplazamiento forzoso, sino que entierra la experiencia de los desplazados, quienes quedan atrapados en la matrices institucionales (Escobar, 1995).

20. Véase, por ejemplo, "Desplazados de la hacienda Bellacruz (Cesar) lograron sus títulos en su nuevo hogar de lbagué". E Tiempo. Bogotá. 4 de mayo de 2004. 


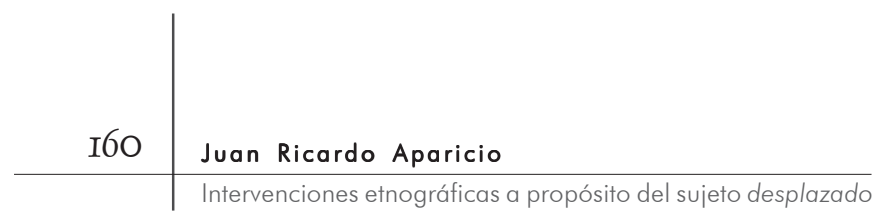

los conocen tan bien como para asesorar a otros desplazados en relación con tutelas, derechos de petición, etcétera. En el trabajo de campo vi, con mucha frecuencia, cartas dirigidas a instituciones como la Red de Solidaridad Social, la Cruz Roja, la Contraloría General de la República, la Corte Constitucional o, incluso, a la Presidencia de la República. La carpeta que compartió conmigo un desplazado en una entrevista -y que contenía quince folios o más de cartas dirigidas a instituciones, derechos de petición, testimonios juramentados frente a las autoridades estatales y al presidente de la república-me hizo pensar sobre si esos bloques, estado y desplazado, están separados o si en realidad viven en una constante continuidad.

Sin duda, existen otras luchas culturales que se distancian de la actividad dentro de los parámetros de la política pública, aunque todavía limitadas en sus alcances o en sus oportunidades para transformar "el orden de las cosas" (Bourdieu, I999) y la condición de marginalidad en la que viven cotidianamente. Como ha analizado Oslender (2004) en el caso del Chocó, las comunidades, sin la presencia del estado, han desarrollado sus propios mecanismos de resistencia al desplazamiento forzoso, mediante sistemas tempranos informales de alarma o redes de solidaridad entre familiares y amistades donde buscar refugio en medio de la guerra. El caso de las comunidades de paz de San José de Apartadó, que en su proceso organizativo y de resistencia colectiva se desligó del estado y declaró su neutralidad frente a todos los actores armados del conflicto, es llamativo al respecto (Uribe, 2004; véase también Hernández y Laegrid, 200I). Es bueno recordar que este proceso colectivo autónomo ha sido objeto también de incursiones de grupos armados, como la ocurrida el 2I de febrero de 2005, en la que uno de sus líderes fue asesinado, junto con varios de sus familiares ${ }^{21}$.

2I. Véanse los siguientes artículos de prensa alrededor de esta tragedia: "'Hoy estamos hablando, mañana podemos estar muertos', presagió líder de Apartadó asesinado". El Tiempo. Bogotá. I9 de marzo de 2005; "San José de Apartadó cumple ocho años de haber sido declarada comunidad de paz". El Tiempo. Bogotá. 2I de marzo de 2005.
Para esta discusión es importante mencionar lo anotado por Vidal (2002), quien ha llamado la atención sobre cómo resulta común que en las instituciones y en la política pública se establezcan diferencias entre desplazados buenos y malos. Los buenos serían los que actúan dentro de los límites establecidos por la política pública, con sus mismos instrumentos, mecanismos, etcétera, y 


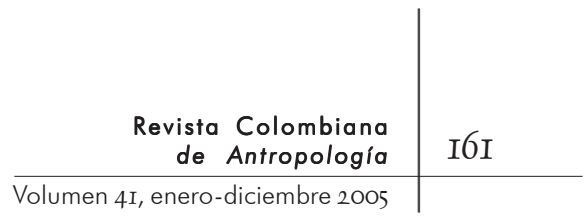

los malos los que en vista del desespero por la negligencia estatal deciden llevar a cabo acciones de hecho, como la toma de instituciones o embajadas. Ahora bien, es claro que moverse dentro de los límites de la política pública no implica, necesariamente, estar comprado por la misma, pues, como he tratado de mostrar, lo interesante es saber qué hacen las personas con esos instrumentos en su cotidianidad, dejando de lado la garantía política o quiza de simple sobrevivencia que haya en esa articulación (Hall, 1997).

Con esas advertencias, entreveo que este tipo de luchas es por entrar como sujetos epistémicos a determinar su propio futuro. Así, por ejemplo, un proyecto elaborado por varios líderes de asociaciones de desplazados, presentado a las instancias respectivas, buscaba ofrecer a las instituciones la posibilidad de contar con un grupo de asesores permanentes, conformado por desplazados por la violencia, con el propósito de que las políticas públicas al respecto fueran más efectivas y coherentes. En el proyecto se encuentran frases que dicen que ellos no se quieren graduar como desplazados; buscaban entonces, mediante un proceso de autogestión coordinada con las instituciones respectivas, ser incluidos como los principales dolientes en la elaboración e interpretación de la política pública sobre desplazados en la ciudad de Bogotá.

Otro ejemplo al respecto es el de las madres cabezas de hogar: en algunas entrevistas manifestaron cómo la experiencia como cabezas de familia les había dado, en sus propias palabras, un espíritu de lucha y sobrevivencia para no desfallecer durante el desarraigo y la llegada a la ciudad en compañía de sus hijos, en condiciones de extrema dificultad. Durante el Seminario internacional de políticas culturales urbanas, realizado en Bogotá en marzo de 2003, una de ellas dijo a los invitados extranjeros que, mientras se celebraba el evento, en la ciudad había un fenómeno de inmensas proporciones: el drama del sinnúmero de familias desplazadas, a las que denominó como "su pueblo", que llegan a la ciudad de Bogotá huyendo de la violencia. Lo último que supe de ella es que trabajaba empacando dulces en una fábrica en el sur de Bogotá. En testimonios recopilados por Sañudo (2003), para mujeres empoderadas políticamente en sus regiones de origen el desplazamiento significó que en su lugar de llegada debieron recluirse una vez más, a su pesar, en la esfera doméstica. 


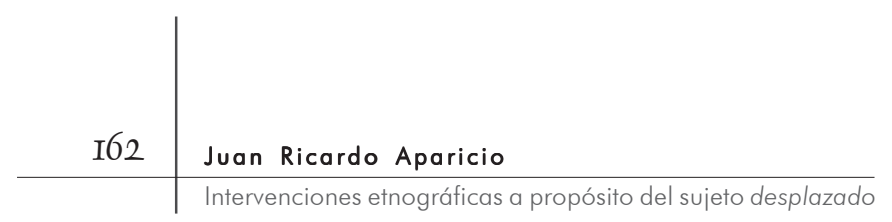

Debo mencionar que un candidato al Concejo de Bogotá a nombre de los desplazados, no obstante la intensa campaña de movilización en las mayores zonas receptoras de desplazados de la ciudad, no salió elegido. Es posible que estas iniciativas hayan sido precisamente eso, iniciativas, pero no hay duda que también existe algo más. Son buenos ejemplos que, a mi modo de ver, junto con el de la megatutela mencionada, permiten entrever una lucha por ese "derecho a tener derechos" (Dagnino, 200I) presente en estas iniciativas, en medio de un sistema que relega a esta población a ser receptora pasiva de ayudas.

\section{Conclusiones}

N I982, EN UnA ENTREvista A Michel Foucault (I990A: I43) Y ReS- pondiendo a una pregunta acerca de cómo consideraría su - obra, él dijo que su papel, insistiendo en que tal palabra (su papel) era demasiado enfática, consistía en enseñar a la gente que es mucho más libre de lo que siente, que la gente acepta como verdad, como evidencia, algunos asertos construidos durante cierto momento de la historia, y que esa pretendida evidencia puede ser criticada y destruida. Esto es, precisamente, lo que he pretendido, y las palabras del pensador francés son la mejor guía para una práctica académica/política que busque desnaturalizar estas verdades, así como sus efectos sobre la población desplazada en diferentes espacios, siendo el de la academia tan sólo uno más, y seguramente no el más efectivo. Esta intención es la que me lleva a presentar ejemplos etnográficos para debatir y cuestionar esas verdades, elaboradas a su vez por operaciones de poder que se mueven en distintas escalas -regionales, nacionales y globales- y que son responsables de intervenir sobre objetos, a su vez, objetos de distintos procedimientos, y ya no sobre personas de carne y hueso.

La intervención etnográfica que aquí sugiero busca cuestionar la consistencia de esas verdades en dos sentidos. Primero, se trata de una intervención que busca vislumbrar y mantener la heterogeneidad de perspectivas que existen entre los mismos desplazados en torno a su situación y sobre las expectativas que tienen para a un futuro, así como frente a la política pública sobre el desplazamiento forzoso en Colombia. Busca contraponer a la 


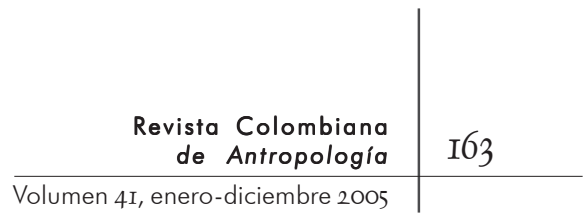

idea de la población desplazada, gobernada por las políticas públicas y toda una serie de instancias paralelas, prácticas de resistencia y de sobrevivencia que no se dejan disciplinar por esta gobernamentalidad. Segundo, busca entender cómo, por qué y en qué condiciones algunas de las personas con las que se discutió integran los discursos de la política pública en su cotidianidad. No pretende la representación banal que busca empaquetar y clausurar "la experiencia del desplazado”. Simple, o tenazmente quizá, le recuerda a este régimen y a las prácticas que se desprenden del mismo cómo los mismos sujetos del discurso construyen su propio devenir en diversas direcciones, al margen y muchas veces contrarias a la voluntad de poder, a pesar de los determinismos y sufrimientos inmersos en este proceso de subjetivación.

En este sentido, desde el punto de vista metodológico se apela a un contexualismo radical, como propondría Grossberg (I997), integrando artículos de prensa, documentos académicos, documentos de política pública, de ONG y, sobre todo, entrevistas con los desplazados, con el propósito de debatir estas verdades. No lo hago por tener la autoridad etnográfica de "haber estado ahí" y conocer de "primera mano" lo que está pasando; sino porque intento poner un obstáculo a la objetivación y estigmatización que se asienta insidiosamente cuando se habla de desplazados en Colombia, de sus problemas y posibles soluciones, así como de sus deseos y expectativas. En términos estratégicos, concibo que este artículo, así como otro tipo de acciones desde otros escenarios, aporta elementos y participa de las luchas necesarias no sólo para subvertir estas verdades sino, sobre todo, para abrir espacios para que los desplazados mismos, como ya lo están haciendo, entren como sujetos epistémicos a determinar su futuro.

\section{BIBLIOGRAFÍA}

Acnur/Defensoría del Pueblo. 1999. Principios rectores de los desplazamientos internos. Bogotá.

ACNur. 2002. Balance de la política de atención a desplazamiento forzado en Colombia 1999-2002. Bogota.

Abrams, Philip. I988 "Notes on the difficulty of studying the State". The Journal of Historical Sociology. I (I). 


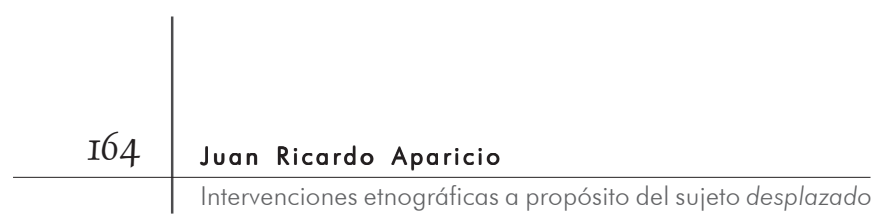

Arextaga, Begoña. 2000. "A fictional reality: Paramilitary death squads and the construction of state terror in Spain". En Jeffrey Sluka (ed.). Death squad: The anthropology of state terror. University of Pennsylvania Press. Philadelphia.

Bello, Martha y Claudia Mosquera. i999. "Desplazados, migrantes y excluidos: actores de las dinámicas urbanas”. En Fernando Cubides y Camilo Domínguez (eds.). Desplazados, migraciones internas y reestructuraciones territoriales. Centro de Estudios Sociales. Bogotá.

Bolívar, IngRID JOHANNA. 2005. "Formación del estado local, repertorios políticos y cultura pública. Un análisis de las marchas del sur de Bolívar en 2000-2002". Ponencia presentada en el panel Transformaciones del estado, poderes locales y cultura política en Colombia. XI Congreso de antropología en Colombia. Santa Fe de Antioquia, 24-26 de agosto de 2005.

Bourdieu, Pierre (dir.). 1999. La miseria del mundo. Fondo de Cultura Económica. Buenos Aires.

Butler, Judith. 200I. "Fundamentos contingentes: el feminismo y la cuestión del posmodernismo". Traducción Moisés Silva. Revista de estudios de género. La ventana. I3.

Castillejo, Alejandro. 2000. La poética de lo otro. Antropología de la guerra, la soledad y el exilio interno en Colombia. Ministerio de Cultura/ICANH/Colciencias. Bogotá.

CAstles, Stephen. 2003. "The international politics of forced migration". Development. Migration: Citizenship, identity and rights. 46 (3).

Chaves, Margarita. 2003. "Cabildos multiétnicos e identidades depuradas”. En Clara Inés García (comp.). Fronteras, territorios y metáforas. Instituto de Estudios Regionales, Universidad de Antioquia. Medellín.

CLIFFORD, JAMEs. 1997. Routes. Travel and translation in the late twentieth century. Harvard University Press. Cambridge.

CodHes. 2004. "Desplazados y confinados en Colombia”. Manuscrito. http://www.codhes.org.co/dsemanal.php?informe $=5 \&$ report $=5$. Marzo I3/2004.

. 2004a. “¿Quién manipula la cifra del desplazamiento?”. 4 de septiembre de 2004. Website: www.codhes.org.co

- 2003. "Reestablecimiento y soluciones integrales. Pronunciamiento de Codhes ante la Corte Constitucional, Bogotá, I9 de agosto de 2003". Manuscrito. Website: http://www.reliefweb.int/ library/documents/2003/codhes-col-3oaug.pdf.

- 1999. Desplazados: huellas de nunca borrar. Casos de Bogotá y Soacha. Arquidiócesis de Bogotá/Codhes. Bogotá. 


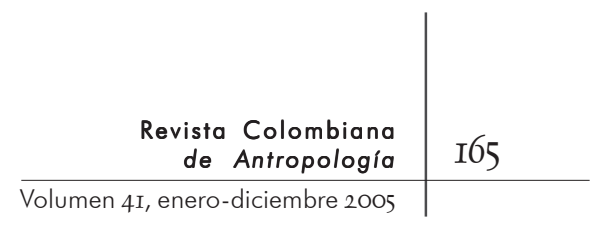

Corte Constitucional. “Sentencia T-025 de 2004”. Magistrado ponente: Manuel José Cepeda Espinosa. Sala tercera de revisión de la Corte Constitucional. Bogotá. 22 de enero de 2004.

. "Auto I78/05”. Referencia: sentencia T-025 de 2004. Órdenes contenidas en los ordinales segundo, cuarto, quinto, octavo y noveno de la parte resolutiva de la sentencia T-025 de 2004, impartidas para superar el estado de cosas inconstitucional en materia de desplazamiento forzado interno. Magistrado ponente: Manuel José Cepeda Espinosa. Bogotá. 29 de agosto de 2005.

DeFEnsoría DEL PueBlo. 200I. "El desplazamiento forzado por la violencia en Colombia”. En Atención a los desplazados. Experiencias institucionales en Colombia. Pontificia Universidad Javeriana, facultad de ciencias jurídicas, departamento de filosofía del derecho. Bogotá.

DENG, FRANCIS. "Report of the Representative of the Secretary-General, Mr. Francis Deng, submitted pursuant to Commission on Human Rights Resolution 1993/95. Addendum: Profiles in displacement: Colombia”. E/CN.4/I995.50/Add.I, 3 October 1994. Comisión de Derechos Humanos. Sesión cincuenta y una. Consejo Económico y Social. Naciones Unidas.

Conpes. Documento 2804 I995. "Programa nacional de atención integral a la población desplazada por la violencia”. Ministerio del InteriorDNP UJS-Degai-Consejería Presidencial para los Derechos Humanos. Bogotá, I3 de septiembre de I995.

Conpes.Documento 3400 2005. "Metas y priorización de recursos presupuestales para atender a la población desplazada de la violencia en Colombia. DNP. Bogotá, 28 de noviembre 2005.

Escobar, Arturo. 2004. "Desplazamiento, desarrollo y modernidad en el Pacífico colombiano”. En E. Restrepo y A. Rojas. Conflicto e (in)visibilidad. Retos en los estudios de la gente negra en Colombia. Editorial Universidad del Cauca. Popayán. Colección Políticas de la alteridad.

. 200I. "Culture sits in places: Reflections on globalism and subaltern strategies of localization”. Political Geography. 20.

- I995. Encountering development. The making and unmaking of the Third World. Princeton University Press. Princeton.

Ferguson, James. I994. The anti-politics machine. "Development", depolitization, and bureaucratic power in Lesotho. University of Minnesota Press. Minessota, Londres.

Ferguson, James y AKhil Gupta. 2005. "Spatializing states”. Toward and ethnography of neoliberal govermentality". En Jonathan Xavier Inda (ed.). Anthropologies of modernity. Foucault, govermentality and life politics. Blackwell Publishers. Oxford. 
Fernández, Amelia y Vidal, Roberto. 2003. "Colombia: The end of displacement or the end of attention". Forced Migration Review. I7. www.fmreview.org/FMRpdfs/FMRI7/fmri7full.pdf

FouCAult, Michel. I976. Vigilar y castigar. Siglo Veintiuno Editores. México.

- 2000. "Govermentality" En James D. Faubion (ed.). The essential works of Foucault, I954-I984. Vol. 3 Power. New Press. Nueva York.

-. I998. "El sujeto y el poder". Texto y Contexto. 35. . I992. "Primera lección. 7 de enero de I976”. Genealogía del racismo. La Piqueta, Madrid.

I990. "Tecnologías del yo". Tecnologías del yo. Y otros textos afines". Ediciones Paidós-Universidad Autónoma de Barcelona. Barcelona.

. I990a. "Verdad, individuo y poder". Tecnologías del yo. Y otros textos afines". Ediciones Paidós-Universidad Autónoma de Barcelona. Barcelona.

I978. History of Sexuality. An Introduction. Volume I. Vintage. Nueva York.

Grossberg, Lawrence. I997. “Cultural studies: What's in a name?”. En Lawrence Grossberg. Bringing it all back home. Duke University Press. Durham

Gual, Luz Elvira, Milena Liñan y Jorcelis Martínez. 2005. “Timayui: lugar receptor y de supervivencia de los desplazados por la violencia en la ciudad de Santa Marta Colombia”. Tesis de pregrado. Departamento de antropología. Universidad del Magdalena, Santa Marta.

GuPTA, AKHIL. I995. "Blurred boundaries: The discourse of corruption, the culture of politics, and the imagined state". American Ethnologist. 22 (2).

Hall, Stuart. I998. "Significado, representación e ideología: Althusser y los debates posestructuralistas”. En J. Curran, D. Morley y V. Walkerdine (eds.). Estudios culturales y comunicación. Paidós. Barcelona.

I997. "The local and the global: Globalization and ethnicity”. En A. King (ed.). Culture, globalization and the world system. Contemporary conditions for the representation of identity. University of Minnesota Press. Minneapolis.

- 1992. "Introduction: Who needs 'identity'?". En S. Hall y P. Dug Gay (eds.). Questions of Cultural Identity. Sage Publications. Londres. 


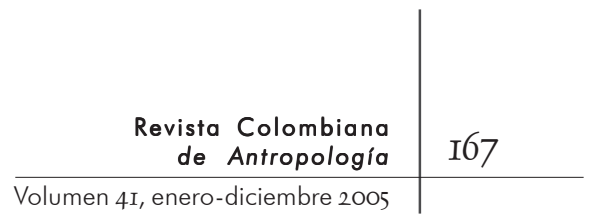

Hernández Delgado, Esperanza y Laegrid, Turid. 200i. "Colombia: Creating peace amid violence. The church, NGO's and the displaced”. En M. Vincent y B. Sørensen (eds.). Caught between borders: Response strategies of the internally displaced. Pluto Press in association with Norwegian Refugee Council. Londres.

Inda, Jonathan Xavier (ed.). 2005. Anthropologies of modernity. Foucault, Govermentality and life politics. Blackwell Publishers. Oxford.

Lui, Robyn. 2004. “The international government of refugees”. En W. Larner y W. Walters. Global govermentality. Governing international spaces. Routledge. Londres, Nueva York.

MALKKI, LISA. I992. "National Geographic: The rooting of peoples and the territorialization of national identity among scholars and refugees". Cultural Anthropology. 7 (I).

. I995. Purity and exile: Violence, memory and national cosmology among Hutu refugees in Tanzania. University of Chicago Press. Chicago.

Marx, Karl. I978. "The German Ideology: Part I”. En Robert C. Tucker (ed.). The Marx-Engels Reader. Segunda edición.

McRobbie, Angela. I996. "Different, youthful, subjectivities". En I. Chambers y L. Curtis (eds.). The postcolonial question. Routledge. Londres.

Mignolo, Walter. 2005. "On subaltern and other agencies”. Ponencia presentada en el seminario The Subaltern and the Popular Workshop. Santa Barbara. 8 y 9 de marzo de 2004.

Museo Nacional de Colombia, división de ARQueología y etNografía/ ICANH. 2003. "Museos cotidianos: espacios de reflexión sobre desplazamiento, identidad y convivencia”. Manuscrito. Bogotá.

Ochoa, Ana María. 2003. Entre los deseos y los derechos. Un ensayo crítico sobre políticas culturales. ICANH. Bogotá.

OSLENDER, UlRICH. 2004. “Geografías del terror y desplazamiento forzado en el Pacífico colombiano: conceptualizando respuestas y buscando soluciones”. En E. Restrepo y A. Rojas. Conflicto e (in)visibilidad. Retos en los estudios de la gente negra en Colombia. Editorial Universidad del Cauca. Popayán. Colección políticas de la alteridad.

Piffano, Germán. 2004. "Desplazamiento forzado interno en Colombia: el falso debate de las cifras”. Ponencia presentada en el seminario Construcción de cifras e indicadores sobre desplazamiento forzado en Colombia. Codhes. 22 de septiembre de 2004. 
Ramírez, María Clemencia. 200I. "Los movimientos cívicos como movimientos sociales en el Putumayo: el poder visible de la sociedad civil y la construcción de una nueva ciudadanía”. En M. Archila y M. Pardo (eds.). Movimientos sociales, estado y democracia en Colombia. CES, Universidad Nacional de Colombia/ICANH. Bogotá.

RED DE SOlidaridad Social. 200I. "Plan estratégico para el manejo del desplazamiento interno forzado por el conflicto armado". En Atención a los desplazados. Experiencias institucionales en Colombia. Pontificia Universidad Javeriana, facultad de ciencias jurídicas, departamento de filosofía del derecho. Bogotá.

SALCEDO, ANDRÉS. 2005. "Etnicidad y ficción en las metrópolis del nuevo milenio". En Jaime Jaramillo Jiménez (comp.). Cultura, identidades y saberes fronterizos. Memorias del Congreso internacional. Nuevos paradigmas transdisciplinarios en las ciencias humanas. Facultad de ciencias humanas. Colección CES.

Sañudo, María Fernanda. 2003. "Reinventando la vida: rupturas y continuidades en los proyectos de vida de mujeres desplazadas por la violencia”. Tesis de maestría. Maestría en desarrollo rural. Pontificia Universidad Javeriana. Facultad de estudios ambientales y rurales. Bogotá.

ScotT, James. 1998. Seeing like a state: How certain schemes to improve the human condition have failed. Yale University Press. New Haven.

Secretariado Nacional de Pastoral Social. 200i. Desplazamiento forzado en Antioquia. Aproximaciones teóricas y metodológicas al desplazamiento de población en Colombia. Conferencia Episcopal de Colombia. Sección de movilidad humana/Universidad de Antioquia. Bogotá.

SORENSEN, BirgitTe REFSLUND. 2003. "Anthropological contributions to forced migration studies: critical analysis and ethnography". Ponencia presentada en Resarching internal displacement: State of the art. Conferencia internacional sobre desplazados internos. 7-8 de febrero. Trondheim, Noruega. Website: www.idp.ntnu.no/Conference/

Steiner Nicklaus, Mark Gibney y Gil Loescher (eds.). 2003. Problems of protection. The UNHCR, refugees and human rights. Routledge. Nueva York y Londres.

SuÁrez, Harvey Danilo. s. F. "Aplazados y desplazados. Violencia, guerra y desplazamiento: el trasfondo cultural del destierro y la exclusión". Documento Codhes. Manuscrito. Website: http://www.codhes.org.co/ hechos/Aplazados\%2oy\%2odesplazados\%2oH.\%2oSu\%Errez.doc 


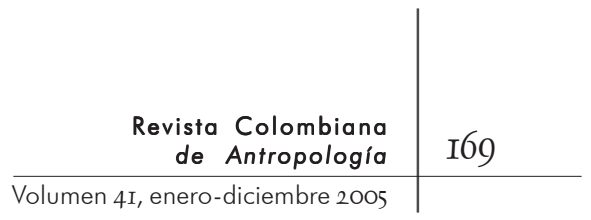

Uribe, María Teresa. 2004. "Emancipación social en un contexto de guerra prolongada. El caso de la Comunidad de Paz de San José de Apartadó”. En B. de Sousa Santos y M. García Villegas (eds.). Emancipación social y violencia en Colombia. Grupo Editorial Norma. Bogotá.

Vidal, Roberto. 2002. "Comentarios al 'Balance de la política de atención a desplazamiento forzado en Colombia I999-2002'”. En Acnur (comp.). Balance de la política de atención a desplazamiento forzado en Colombia 1999-2002. Bogotá.

Recibido: 5 de noviembre de 2004.

Aprobado: I7 de noviembre de 2005. 